\title{
Confessional Culture
}

The current crisis of privacy is, or ought to be, especially surprising in the United States, because privacy concerns, historians and legal scholars attest, were a prime driver in the creation of the nation, and the erection and expansion of our basic freedoms. Our disregard for privacy is surprising for another reason: it defies predictions and expectations of how we are supposed to act under surveillance. Why, if we know we are watched - and we admit as much - is online behavior so shameless, seemingly open and free? Why do so many of us feel compelled to blare intimate details, and share mundane and embarrassing events with the whole world? What does that say about us? Is human nature changing before our very eyes, in the digital age, such that we show no compunction about living an utterly public life, in most all respects? How can we retain any enduring or grudging respect for privacy in this brave new world? Some people muster objections; some admit there is something wrong in privacy invasions - but what? We have a vocabulary of privacy, and a deep historical relationship to it (or so we are told), but hardly know what it means anymore, why it is of value, and worthy of defense. And in the digital age, privacy requires no modest or ordinary defense, but a monumental call to arms, to beat back the tidal wave of surveillance - which we invite, and facilitate.

Privacy is not mentioned in the US Constitution. Nevertheless, scholars have argued that privacy protections stem from the values and experiences of the nation's founders, and are clearly implied in the Bill of Rights. In one respect, "the history of America is the history of the right to privacy." From the inception of this nation, immigrants were driven here by privacy concerns of a kind. The Pilgrims departed England, for example, because they wanted to

1 Frederick S. Lane, American Privacy (Boston: Beacon Press, 2009), 1. 
be left alone in peace to practice their faith. And the colonial struggle with England was galvanized by controversies over privacy invasions.

The seeds of the Revolutionary War were sown in the dispute over who would bear the cost of the French Indian War, and the ongoing efforts to protect the American frontier and the empire at large. Britain claimed that the colonists needed to bear a greater burden of the costs of such defenses. The colonists objected, and sought to avoid taxation by concealing the fruits of their trade. In Massachusetts in 1755, the English government tried to raise funds by issuing "writs of assistance," which authorized custom house officers to "randomly search sailing ships, dockside warehouses and even private homes for untaxed property." The colonists chafed under this policy, and opposed efforts to renew the writs upon the death of King George II in 1760. In the hearing for their renewal, colonial lawyer James Otis eloquently articulated the opposition. "One of the most essential branches of English liberty is the freedom of one's house," Otis claimed. "A man's house is his castle; and whilst he is quiet, he is well guarded as a prince in his castle. This writ [of assistance], if it should be declared legal, would totally annihilate this privilege." 3 Otis cites a long-standing element of English Common Law known as Castle Doctrine - "one's home is his castle," a sacrosanct space where he is most perfectly free. Castle Doctrine is still prominently invoked in US law today, in, among other things, self-defense and gun rights concerns. Courts have recognized a robust right of self-defense for individuals wielding guns in the home, against unwanted strangers.

The concern for privacy became a major driver of the Revolutionary War, and though the term does not appear in our founding documents, its influence can be detected - and privacy protections inferred. In the Bill of Rights, for example, the Third Amendment, which prohibits soldiers being quartered in one's home, is a clear reaction against British efforts to do the same, invading and occupying colonists' private dwellings. The First Amendment protects our right to make up our minds privately, regarding political and religious affiliation. The Fourth Amendment, which protects against "unreasonable searches and seizures" of the citizenry, such as the British soldiers perpetrated, prominently articulates privacy concerns. In the 196os, Fourth Amendment jurisprudence becomes the bedrock of a constitutional right to privacy recognized by the Supreme Court.

Prior to that, however, privacy makes a notable appearance on the US legal scene in the 1890 s thanks to an influential article written by Samuel Warren

Lane, 10-11.

3 Lane, 12. 
and the future Supreme Court Justice Louis Brandeis. Attempting to express an explicit right to privacy, which they felt was lacking, Brandeis and Warren claim that it amounts to or consists in a "right to be left alone." The US Constitution and English Common Law (which is our Constitution's forbear and foundation) recognize a citizen's right to be protected from intrusion in his person and property. But, Brandeis and Warren explain, times had changed; new technology had emerged, and advanced civilization revealed a new realm in need of defense beyond the merely physical, namely, "man's spiritual nature ... his feelings and his intellect." 4 US law had evolved to offer protection for intellectual property, the men point out. But this was insufficient to combat attacks on our emotional well-being, which privacy invasions constituted.

Brandeis and Warren are concerned primarily with gossip, and how technological innovations embolden and empower the gossip mongers, and stoke the general appetite for their wares. A more immediate motivation for their article, it seems, was Warren's annoyance at the exuberant media coverage of his daughter's wedding. The men single out "instantaneous photographs," a new invention at the time, and the "newspaper enterprise" that disseminates them to a hungry public. The latter spurred journalists to pry more deeply into private lives, recording intimate details for posterity. "The press is overstepping in every direction the obvious bonds of propriety and of decency," Brandeis and Warren complain. "To satisfy a prurient taste, the details of sexual relations are spread broadcast in the columns of daily papers. To occupy the indolent, column upon column is filled with idle gossip, which can only be procured by intrusion upon the domestic circle." ${ }^{5}$

They feel they are dealing with a new breed of offense, which is somewhat abstract - the feelings of hurt, or anger, or irritation that emerge when insight into one's private life and emotions are disseminated to the curious, simply for curiosity's sake. And when people hungrily absorb the details of private lives, this media indulgence promotes immoral behavior - prurience and indolence. This seems to be the focus of Brandeis and Warren's ire, as opposed to the offense in privacy invasions, for those whose privacy is invaded. They are more confident in articulating, and more intent in highlighting, the ill that is media gossip, which "both belittles and perverts men," than explaining exactly why and how privacy invasions hurt those whose lives are invaded. ${ }^{6}$ This is a recurring theme

4 Louis Brandeis and Samuel Warren, "The Right to Privacy," Harvard Law Review IV, 5 (1890). http://groups.csail.mit.edu/mac/classes/6.805/articles/privacy/Privacy_brand_warrz.html.

5 Brandeis and Warren.

6 Brandeis and Warren. 
going forward: while the hurt from invaded privacy is felt, the offense - to those whose lives are exposed - is difficult to pinpoint or spell out. As a result, privacy protections become hard to justify, and easy to surrender.

Law evolves to offer protection for more abstract aspects of our lives, Brandeis and Warren maintain. Such is its natural progression, and it is the result of advancing civilization. Civilization satisfies our basic physical needs, and teaches that happiness consists in more than the satisfaction of those needs. Rather, happiness has a significant emotional and spiritual component. Intellectual property rights are one such creation of advanced civilization and mature jurisprudence, protecting intangible goods - prosecuting people who steal our ideas, for example, preserving ownership and authorship. To that extent, intellectual property protection might seem like a good jumping off point for defending against privacy invasions. But Brandeis and Warren argue it's the other way around. The foundation of intellectual property protections is not private property, but "inviolate personality," that is, the notion of a sacrosanct personal space that ought not be invaded or robbed or exposed under any circumstances. ${ }^{7}$ The right to be let alone is a foundational right, a precedent right in common law, which then infuses our Constitution. Until Brandeis and Warren put pen to paper, it was only in need of being pronounced; its growing and newfound significance was made clear by evolving technology and evolving culture.

Only in the 1960s, when the US Supreme Court was presided over by Justice Earl Warren, did the right to privacy receive the full legal recognition and sanction that Brandeis and Warren anticipated. The term "privacy" is pronounced in only 88 Supreme Court cases prior to the 1960s, but in 107 cases under Earl Warren's tenure, suggesting that "the Warren Court made privacy a central legal concept in American law." ${ }^{8}$ Justice William O. Douglas was its chief evangelizer. In one notable case, Griswold v. Connecticut, Douglas wrote the majority opinion, and explained that while certain rights are not explicitly mentioned in the Constitution or under any single provision of the document, they become evident if we would hope to fully enact the provisions of the Bill of Rights. ${ }^{9}$ The right to privacy is one such right - and is implied by the First Amendment. We cannot exercise freedom of speech, assembly, or religion without an antecedent right to privacy, which creates an inviolate zone that government, or other powers and interests, dare not trespass. Of itself, the First

Lane, 153-4.

Griswold v. Connecticut, $3^{81}$ US 479 (1965). 
Amendment implies a right to privacy, but other provisions combine to carve out a space where we must be let alone, in order to fully enjoy the freedoms spelled out in the Constitution.

Strikingly, Douglas aims to lend privacy an air of longevity, declaring that the institution is "older than the Bill of Rights - older than our political parties, older than our school system." ${ }^{\text {"10 }}$ Privacy is as old as the institution of marriage, too, he claims, which is at issue in the case at hand, concerning the state of Connecticut's right to prohibit married couples from learning about contraception. Marriage is a sacred institution, Douglas maintains, and privacy is essential for protecting the intimacy of this bond. This claim is dubious on a few fronts. For one thing, as we will see in Chapter 5 , the notion of privacy is hardly monolithic or eternal, but has changed over the centuries. What's more, marriage has changed, too; the institution that Douglas hails was not in fact the repository of sacred intimacy in times past.

In a later case, Papachristou v. City of Jacksonville, Douglas invokes the right to be let alone in the case of those accused of loitering and wandering where they are not wanted or permitted. We have a right to meander, uninterrupted and uninterfered because it is one of those private activities "responsible for giving our people the feeling of independence and self-confidence, the feeling of creativity," which is the lifeblood of democracy. ${ }^{11}$ Democracy requires that privacy be protected, because it nurtures an independent spirit, and emboldens citizens to experiment, with their travels as with their thoughts. People in a democracy should feel free to speak out, unconstrained by social pressure, perhaps liable to uttering what is wild and offensive on occasion, because this is the ground of dissent, which expands the frontier of liberty in unexpected ways. Douglas leveled this argument against the backdrop of the civil rights movement, whose proponents had to persevere amidst immense social pressure, and outright oppression. It was clear to him, as to many, that privacy is a necessary protection for the expansion of rights that we soon take for granted. Individuals must be allowed to consider, cultivate and express potentially dangerous ideas, free from the intrusion and coercion of social forces intent on maintaining stability, and the status quo.

Privacy and personal independence are inseparable, according to Douglas, and, tellingly, he invokes Thoreau in this regard. Thoreau and his mentor Emerson eloquently and memorably celebrate a strong brand of American individualism, perhaps the quintessential expression thereof. And their account presumes no small degree of privacy, protecting the individual from

10 Griswold v. Connecticut, 381 US 479 (1965).

11 Papachristou v. City of Jacksonville, 405 US 156 (1972). 
the corrupting influence of society, secluding him as far as possible, so that he might hear the authentic voice of his conscience - and more. It is an account that clearly resonates in later iterations and defenses of privacy.

Douglas admires Thoreau's "Walking," which endorses an individual's free and unplanned departure into nature, sauntering in the fields with no prescribed agenda or plan. One is purified in this venture, Thoreau maintains, liberated and opened to hear the voice of truth, which a person can only detect when alone with his thoughts. Society compels us to focus on economic gain, and the lures of wealth and class, none of which truly fulfills us. To the contrary, society infects us with a kind of madness. Unfortunately, we are born into its bondage, which is why so many people take for granted the economic and social demands placed on us, and mindlessly heed them. But real freedom beckons nearby. We only need to stride out into the fields and woods - alone.

In a famous ode to our rightful independence, Thoreau declares that society has us "study the laws of matter at and for our convenience, but a successful life knows no law. It is an unfortunate discovery ... that of a law which binds us where we did not know before that we were bound. Live free child of the mist!"12 To discover authentic existence, and live fully, we must detach ourselves from the laws of men. In so doing, we find favor with God, and emulate how He also transcends law - the law of Nature. On one hand, alone in the wilds, we may finally enjoy the peace and quiet to hear the voice of God, and discern his will. In liberating ourselves from human law in this manner, furthermore, we emulate God, the creator of the laws of Nature, who also transcends them.

Thoreau engages in a more elaborate and insistent exercise in selfpurification at Walden Pond, where he holes up in a cabin on land owned by his friend Emerson. Embarking on this two-year experiment, Thoreau declares that he will learn how to live deliberately, that is, simply, thoughtfully, consciously. He will isolate and identify his real needs, which he suspects are few. Society dictates that our needs are many, and then sends us endlessly chasing their fulfillment - creating new needs all the while. This is a lie, an unnecessary complication. Authentic living, real living, can only be achieved through a kind of separation and isolation - privacy, if you will. Thoreau constructs the cabin himself, bereft of creature comforts; he grows and forages for food, drinks from the stream, and bathes in the pond. He sits on his doorstep listening to the birds, contemplating the sights and sounds around him, straining to detect the immanent wisdom of nature. Most of all, however,

12 Henry David Thoreau, "Walking," in Nature/Walking (Boston: Beacon Press, 1991), 113-14. 
Thoreau quiets the din of outside voices, voices that issue demands, fears, worries, and concerns, which, when immersed in the workaday world, seem utterly normal. From his perch, aloof and apart from the common worries of men, their ridiculous nature is readily apparent. Everyone would do well to enjoy this kind of privacy, even for a while, and box out all the chatter. "Let us settle ourselves and work and wedge our feet downward through the mud and slush of opinion and prejudice and tradition and delusion and appearance ... till we come to a hard bottom and rocks in their place, which we call reality." ${ }^{13}$

Thoreau is moved to compassion at the sight of his peers, weighed down with needless concerns, driven by insatiable and nonsensical social pressures. But Emerson, his intellectual ally, depicts society as nothing less than an adversary; one must be utterly insulated against its assaults and corruptions. A person is properly "Self-Reliant," Emerson argues in his famous essay celebrating individualism. If you would attain the truth and discover the sacred kernel of life, you must ruthlessly block off outside influence and look within. Thoreau relishes his time at Walden Pond, for it reveals the eternal wisdom of the philosophers he has read - it makes clear the truths others have taught for generations. For Emerson, however, you must strike out on a radically new and independent path to attain wisdom. "When good is near you, when you have life in yourself, it is not by any known or accustomed way; you should not discern the footprints of any other; you shall not see the face of man; you shall not hear any name - the way, the thought, the good shall be wholly strange and new." ${ }^{4}$ Society has nothing to recommend you - nor does history, or tradition, it seems.

Nature is a conduit to authenticity, by this account. Or better yet, nature is the purifying force or milieu that makes each of us a conduit for the truth - an empty vessel for the divine. "In the woods," alone, Emerson writes, "all mean egoism vanishes. I become a transparent eyeball; I am nothing; I see all; the currents of the Universal Being circulate through me; I am part or particle of God." 15 I need not physically remove myself from society to enjoy this vision. I can learn to commune with nature in quiet moments when it offers itself to me - which can be anywhere. I must practice the art of solitude, and embrace sacred loneliness whenever possible. Emerson describes doing so while crossing the town commons in the snow, enveloped in silence, and stopping to gaze up at the stars; suddenly, he is one with them.

13 Henry David Thoreau, Walden (New York: Dover Publications, 1995), 16.

14 Ralph Waldo Emerson, "Self-Reliance," in Nature and Selected Essays (New York: Penguin Books, 1982), 181.

15 Ralph Waldo Emerson, "Nature," in Nature/Walking (Boston: Beacon Press, 1991), 8. 
Emerson and Thoreau offer an account of individualism that will be essential for privacy advocates: if I am to be a proper individual, robust and self-determining, authentic and in touch with "reality," I must filter out external influences and prejudices. I must heed only the voice that wells up within - provided I am able and allowed to hear it. This will prove to be a high bar for privacy, indeed.

The legal, cultural and political forces elevating privacy arguably culminated in the twentieth century, such that privacy became a "fixation ... of US public culture," where it has been "foundational to [our] sense of personhood and national identity." ${ }^{16}$ Indeed, the language of privacy is very familiar to us, ingrained as it is in our national narrative and legal system. We instinctively know that privacy matters, and thus find it perfectly normal, or at least unremarkable, when privacy is invoked in public commentary or political speeches. And as I will soon argue, the concern for privacy is still operative or manifest in certain quarters of our lives, in some form or fashion. For the most part, however, in our daily behavior - in cases where privacy concerns should figure prominently - we tend to forsake it with little thought or compunction. Which suggests that, in practice, privacy rings hollow. Few people seem to know what it really means, what it consists in, why it ought to be defended - nor do they seem to care. It attests to a stark disconnect in our culture. Some may retort (or complain) that we hear about privacy incessantly; it is hardly a lost value or norm, but something that still reverberates in our society - the media is littered with its mention. I would contend that the people who matter are not the ones raising the issue, bandying it about, championing it - cherishing it. Increasingly privacy concerns emanate from a select population of scholars, advocates, journalists, and policy makers. And their arguments and warnings do not seem to resonate with the general population. An effective defense of privacy, such as we would require in the digital age, demands a deeper, broader foundation.

For digital technology has made privacy so much more vulnerable, and, in 2013, Edward Snowden exposed an expansive spying program, carried out by the US government, to collect copious amounts of information about its own citizen population, from the digital trails we leave behind in our daily business. Unique to this age and economy is how we, who know that our digital behavior exposes intimate details of our private lives, largely assist our monitors, readily and continuously offering up personal information. To be specific, Snowden, a former contractor for the National Security Agency (NSA), uncovered its PRISM program, which collects data on our digital interactions from major

16 Sarah Igo, The Known Citizen (Cambridge, MA: Harvard University Press, 2018), 2, 4. 
internet companies, with their compliance. The budget for this program was relatively small (\$20 million), suggesting how easy it is for government spies to gather the desired information. ${ }^{17}$ We practically volunteer the information. Political philosophers and theorists have long warned that privacy is a prime target of ruling powers, who would happily invade it in order to subdue or control us. What's new today is that we the citizens join in its destruction - actually, we are the principal agents of its demise. The NSA, and anyone else interested in monitoring us (and they are legion) only has to sit back; the intimate details of our lives fall into their laps.

Snowden's revelations were not, nor should have been, terribly surprising to most, upon minimal reflection. Since the War on Terror ramped up last decade, it was well known that the US government was interested in spying on its citizens, and anyone else. Almost immediately after the 9-11 attacks, the Bush administration authorized the NSA to eavesdrop on US citizens and residents, searching for evidence of new terrorist plots. ${ }^{18}$ It was revealed at the time that the government had pressured communications companies to enable said eavesdropping, and the government seemed to back off - temporarily. Thus, the American population knew that widespread surveillance of the home population was a likely temptation for our ruling parties, and a perennial threat. And when Snowden revealed the NSA spying operations, there was a profound outcry - at least publicly, and in the press. Scholars, politicians, and civil rights advocates bemoaned the news, and still do for the most part. But average citizens were not impressed, it seems. One study noted that only about a third of those familiar with Snowden's revelations were motivated to improve privacy measures as a result. ${ }^{19}$ And in fact, according to another study released soon after Snowden's leak, a majority favored NSA efforts to "[track] the telephone records of millions of Americans," and felt "it is important for the federal government to investigate possible terrorist threats, even if it intrudes on personal privacy." ${ }^{20}$

A summary report three years later suggested that Snowden's revelations were perhaps even less impactful. Subsequent terror attacks prompted people

17 Leo Kelion, “Q\&A: NSA’s Prism Internet Surveillance Scheme," BBC.com, July 1, 2013, www .bbc.com/news/technology-23051248.

18 Eric Lichtblau and James Risen, "Bush lets U.S. spy on callers without courts," New York Times, December 16, 2005, www.nytimes.com/2005/12/16/politics/bush-lets-us-spy-on-callerswithout-courts.html.

19 "CIGI-IPSOS Global Survey on Internet Security and Trust," Centre for International Governance Innovation and IPSOS, November 24, 2014, www.cigionline.org/sites/default/files/ documents/internet-survey-2014-slides.pdf.

2o "Majority views NSA phone tracking as acceptable anti-terror tactic," Pew Research Center, June 10, 2013, www.people-press.org/2013/06/10/majority-views-nsa-phone-tracking-as-acceptableanti-terror-tactic/. 
to worry more that national security programs did not go far enough in fighting terror, and were less concerned about civil rights protections, in comparison. ${ }^{21}$ Most people have taken modest measures to protect privacy online, but the Snowden affair did not inspire widespread adoption of anything more sophisticated which might prove a greater obstacle for NSA spying. ${ }^{22}$ Of course, many plead ignorance about sophisticated programs to protect their privacy. They say they would like to do more to protect their data, but are not aware of the best, most effective options. And many remain cynical that they could still elude government surveillance, even after enacting available privacy protection measures. What's more - and what is perhaps especially frustrating for privacy advocates and Snowden doomsayers - most people report that they are not principally worried to block out government spying. Among those who took measures to maintain anonymity online, they indicate that they sought to "avoid 'social surveillance' by friends and colleagues rather than the government or law enforcement." ${ }^{23}$ In fact, government and police are dead last among potential monitors that internet users wish to elude. ${ }^{24}$

Political theorists will find this troubling because governments have proven to be a serious threat when they have access to and collect our sensitive personal information. This lends government immense power, which is too easy to abuse, and often leads to and assists oppression. Some argue that the destruction of privacy was essential to twentieth-century totalitarian regimes that aimed at nothing less than total domination of the citizen population. And there is something almost obscene in the fact that Americans of all people are so little concerned with government surveillance, and more worried about snooping family and friends. Protecting our privacy is a central lesson of our nation's history. If we learn anything from the birth of our nation and its founding documents, it's that privacy - from government intrusion - is a supreme virtue and must be jealously defended.

I suspect most Americans know this one way or another; or they should, if they paid attention to their history. Most of us instinctively affirm that privacy is an important value, worthy of protection, if not reverence. As I have argued, we are steeped in a tradition of privacy, from accounts of our history, to essential legal arguments, and our very notion of individualism. Perhaps this is why we will say we care about privacy, and would like to do a better job

Lee Rainie, "The state of privacy in America," Pew Research Center, September 21, 2016, www .pewresearch.org/fact-tank/2016/og/21/the-state-of-privacy-in-america/.

22 Rainie, "The state of privacy in America."

23 Rainie, "The state of privacy in America."

24 "The state of privacy in post-Snowden America," Pew Research Center, September 21, 2016, www.pewresearch.org/fact-tank/2016/og/21/the-state-of-privacy-in-america/. 
protecting it - and we are uncomfortable with expansive and invasive government surveillance programs. But our behavior indicates something else.

Most consumers say that they are eager to receive discounts and promotions from retailers, but not at the cost of divulging personal information. ${ }^{25}$ However, they quickly dispense with their purported trepidation when the rubber hits the road. Retailers know this, and justify their snooping on the basis of tradeoffs: so long as customers receive ample benefits in exchange for divulging personal information - and personalized advertising is the most effective - they will submit to pervasive surveillance. Researchers confirm this. When asked in the abstract, consumers reject the idea of tradeoffs; but when presented with a "real-life tradeoff case - asking ... whether they would take discounts in exchange for allowing their supermarket to collect information about their grocery purchases" - a very common practice, I might add - "more than twice as many ... say yes to tradeoffs."26

A striking feature of the digital age is that we, individual citizens - eager consumers and avid social media users - hand over personal information to those who watch us. We subscribe to tradeoffs with retailers and social media giants, even when the rewards for exposure are minimal. We do this willingly, in some cases happily, and are not so timid or careful or concerned about displaying our most intimate details, eccentric whims, or caustic opinions. This is a surprising turn of events for many political thinkers, who have long warned that mass surveillance strips us of a feeling of personal freedom, and makes us less liable to speak out and express individual differences, unique opinions, whims, tastes.

In short, a confessional culture is ascendant in the digital age, and this flies in the face of dire predictions about panopticism. Panopticism refers to the surveillance scheme designed by eighteenth-century social reformer Jeremy Bentham, and which he first intended for a prison. His panoptic prison was to be a circular structure with inmates housed in cells around a central tower, whose occupant is obscured, his watchful eye unseen. This structure was revelatory, and widely inspirational, because it illustrates a highly efficient use of power. Consider: you don't need someone literally occupying the tower; if obscured, the inmates never know for sure if or when they are watched - but will behave as if they always are. In this way, "visibility is a trap," as the philosopher Michel Foucault puts it. ${ }^{27}$ The

25 Joseph Turow, The Aisles Have Eyes (New Haven, CT: Yale University Press, 2017), 158.

26 Nora Draper, Michael Hennessy and Joseph Turow, “The Tradeoff Fallacy," A Report from the Annenberg School for Communication, University of Pennsylvania, www.asc.upenn.edu /sites/default/files/TradeoffFallacy_1.pdf.

27 Michel Foucault, Discipline and Punish, trans. Alan Sheridan (New York: Vintage Books, 1995), 200. 
intention is that inmates might internalize the spectral watchman, and discipline themselves.

And Bentham had high hopes for the impact and influence of the panoptic schema outside the prison walls. If implemented in a variety of venues across society, people would be motivated to behave morally, work diligently, and become better persons and citizens all around. Widespread, perhaps even pervasive panopticism would keep everyone "on the up and up," so to speak, invigorate the economy, improve general well-being, diminish the social welfare state, and lighten the load on government, police, and church, tasked with keeping us all in line. Indeed, Bentham's bold prediction proved tantalizing, and Foucault details how this political revelation was applied throughout the state and society, from schools to factories to hospitals.

From a political perspective, physical force is inefficient in exerting control. It is often expensive, and it can also backfire: extreme force exerted by those in charge might cause people to lash out and revolt. This is most clearly the case for people who are accustomed to freedom, as Machiavelli would say - or people who fancy themselves free, as in a democracy. Surveillance provides an elegant and devastatingly effective solution for powers intent on ruling, and perhaps oppressing, in a democratic age. The architecture of surveillance is "so light," Foucault liked to say; it is subtle, hardly noticeable. It only requires open spaces, through which people can be watched - and watch one another. In this respectand perversely - methods of surveillance can be easily commingled with or couched within euphemistic calls for openness, transparency, letting in the light. And, in another perversion, Foucault says, we start to see panoptic schemas used to enhance growing disciplinary power that imbues incipient democracies in the nineteenth century, stymying the personal freedoms they promised.

Actually, if we consider its relation to democracy, this gets to the heart of what makes panopticism so powerful and insidious. Panoptic surveillance also fits nicely with the rhetoric and ideology of individualism, because, well, it succeeds so well at individualizing - but not in a good, empowering way. Rather, individuals wither under the spotlight. And in their loneliness, and growing paranoia, they turn into agents of their spies. Consider again Bentham's plan: at the heart of his prison is a spectral watchman - a vague, ominous presence. This vagueness is key, and essential to the supposed efficiency of his system. We, the spied upon, may not know who our spies are exactly, what they want, what they are on the lookout for - what they are soon to punish us for, perhaps. Much is left to the imagination, where it does its critical damage. The spied upon are only supposed to see one another, and in their lateral relations, through their own watchful, worried eyes, compel 
one another to keep in line - whatever that might mean, exactly. It's better if we are left guessing about that too, to some extent. The result will be that we the watched are reduced to a kind of paranoia, where we are less than free.

Surveillance makes power anonymous, also automatic. ${ }^{28}$ Power will not be exerted top-down or from without, in rough imperious fashion, sure to rankle the democratic masses. In panoptic schema, rather, power operates from within each individual - at his or her own behest. Because I do not know precisely who I am curtailing my behavior for, and how, this will largely seem self-directed. And I will seem free and self-determining throughout. With this, we arrive at the full genius of panopticism: it leaves us feeling autonomous and independent, but compliant and chastened instead. And we are the primary agents of social conformity and political obedience, which, depending on the nature and extent of the panoptic scheme employed, Foucault argued, can be stifling indeed.

In many ways, the modern surveillance state has far surpassed Bentham's aspirations - so much so that the title "surveillance state" hardly fits the bill. Retailers, for example, are deeply invested in monitoring us, too, and throughout our daily lives, in a host of hidden ways - shadowing our every move, tracking our every want and whim. The immensity, complexity, and immanence of contemporary surveillance systems has prompted critics to come up with titles that capture it better, like "tenticular oligarcy," or "Big Other," as opposed to Big Brother - conveying the ominous anonymity of our current spies. $^{29}$

Networked digital technology seems the ideal tool to achieve the power dynamic Foucault says is so devastatingly effective in keeping people underfoot in democracies. In terms of the architecture of surveillance, one can hardly imagine anything so "light" or subtle as digital media. I may steer clear of certain websites, forums, or chat groups, and watch what I say and do online, for fear of who is watching me, and what their agenda is. And my censorship will seem self-directed. Thus, we are all silently, covertly - obligingly and automatically - urged towards conformity and quiescence.

Except that this is not how things have turned out. Or so it seems. By and large, the digital generation does not appear to behave online as if some disapproving Big Brother (or Big Other) were watching our every move, influencing our every decision, paralyzing us with fear, and demanding self-

28 Foucault, 176.

29 See respectively Bernard Harcourt, Exposed (Cambridge, MA: Harvard University Press, 2015), 79; and Shoshana Zuboff, The Age of Surveillance Capitalism (New York: Public Affairs, 2019), 20. 
censorship. Quite to the contrary, on social media, people are prone to divulging all manner of mundane, intimate, or unsavory details of their personal lives, with little evident concern for the shadowy agents listening in - or even what their friends, family, and co-workers (or bosses) might think.

Facebook users issue "status updates" reporting where they are at any given moment, no matter how ordinary or insignificant - or embarrassing. Social media platforms offer people the opportunity to report how they feel on a nearconstant basis, declaring emotional highs and lows, relating caustic social and political views, sharing lascivious desires. I think of former (and beloved) students I had to block on Facebook, lest their political tirades became too wrathful and foul-mouthed, if my children should spy them over my shoulder or their sexual confessions became too frank, bawdy, and detailed. Oftentimes, their stories and rants made me wonder, do they even think about their audience, witness to these emissions? Do they forget that I - or their grandparents, or professional contacts, or bosses - might be party to them? Do they just ignore who will see their posts? Or if they do recognize their audience, do they simply not care about embarrassing themselves or others? This confessional culture is not limited to millennials and former students, of course. I am routinely shocked by gushing or careless posts from older peers on social media, who say things they should know better than to share, if they hewed to older, pre-internet rules of etiquette. I think in particular of one forty-plus Facebook friend who is an exultant new mother, and divulges every thought about her child, and shares every momentous detail of his existence - and who can begrudge her excitement, really? But then she broaches a new frontier, and posts close-up pictures of her breastfeeding, which leaves little to the imagination. Some have dubbed these "brelfies," and apparently this is a widespread phenomenon in the digital age. ${ }^{30}$ While this phenomenon may have admirable intentions, normalizing breastfeeding, or celebrating motherhood and the female form, it defies anticipations for surveillance, which should prompt us to hide ourselves, or curtail eccentric, highly personal behavior.

Our confessional culture has arguably been brewing for some time now, and before the emergence of social media - perhaps even as far back as the social and political revolutions of the 196os, when people came to embrace their sexual identities and predilections, and speak about them openly and frankly. ${ }^{31}$ The 1990 boom in memoir writing, and the popularity of Reality TV

30 See, for example, Lucy Waterlow, "Rise of the Brelfie," Daily Mail Online, February 25, 2015, www.dailymail.co.uk/femail/article-2968246/Mums-head-head-brelfie-Morning-breastfeed ing-selfies-list-parenting-trends-thanks-stars-like-Miranda-Kerr.html.

${ }^{31} \quad$ Igo, 268. 
shows shone a bright light on otherwise mundane and unsavory details of

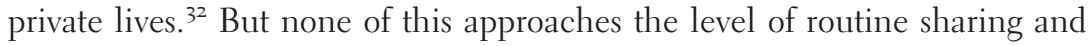
deep exposure we now expect on social media. The sexual liberation movement, the memoirs, and Reality TV made it acceptable for personal, shameful details to be revealed; they made the prospect of exposure less fearsome, or horrifying, and even a bit therapeutic. With social media, however, confession is pervasive: people share routinely, and as a matter of fact - unprompted, and often unconcerned for norms transgressed or defied. Indeed, this has become so common, and people so nonchalant about sharing details that would have been embarrassing in an earlier age, that universities and employers regularly scour applicants' social media platforms in search of troubling behavior and opinions. And though this is widely known and reported, many persist in baring their souls and lives nonetheless.

We know we are watched online and in social media; we know we are monitored by our government, and, increasingly, commercial interests, too. When prompted, many of us will say we disapprove, but, by and large, we do not behave like we knew or cared about the spying, or reckoned with its implications. We do not behave as if we inhabited a digital panopticon, or tenticular oligarchy, or what have you. Why?

Philosophers have long argued that human consciousness is inherently narrative: this is a major way we seek to understand and give meaning to reality, and human existence. Specifically, we aim to project a narrative structure onto our lives - give them a beginning, climax, and hopefully a fitting conclusion - and also situate them within a greater narrative, be it social, historical, or cosmic. Thanks to social media, we get to curate the stories of our lives - in real time and, if need be, change characters, dominant plot lines, or background themes how and when we like. Or, in documenting everyday events and occurrences, we may elevate them and memorialize them for posterity. Suddenly our chores, the many stops we make throughout the workday, gain special significance in being shared - and, of course, connections are made, satisfying our inherent need to socialize and build bonds. And in this respect, our digitally curated lives fit into another great American tradition: entrepreneurship. ${ }^{33}$ We are busy constructing an identity and life story - a brand - that we then champion and market, like everyone else selling something in this country.

This implies that there is also a competitive element to the social media sharing. It is increasingly common for people to boast about their romantic

32 Igo, 338-44.

33 Harcourt has made a similar argument. Cf. Exposed, 99. 
relationships in digital platforms, for example, and post substantiating pictures and gushing proclamations and confessions, complete with "weekiversary posts" diligently marking the duration of the relationship. ${ }^{34}$ This has the unintended (or perhaps intended) consequence of shaming people who are not in love, or people who may now doubt the intensity of their own romance, and then wonder why they or their partner are not similarly bragging about it online. Apparently, this phenomenon has goaded some people to stay in relationships longer than they should have, just for the sake of "keeping up with the Joneses" online. ${ }^{35}$ They make their romances seem more devoted and titillating than they are, and persist in the fantasy - which comes to supplant the real thing. Consider the title of a recent article documenting this trend: "Are you really in love if it's not on Instagram?" Romance is not real if it's not announced and performed on social media.

We might pay special attention to millennials, in this regard, since they are the generation growing up with, and on, social media - and they seem to be the most egregious sharers online. In one respect, they are not really doing anything too exceptional for young people - they are only taking advantage of new technology to do what previous generations have always done: socialize with a fury, and in ways that may seem strange, uncomfortable, or even dangerous to parents and elders, publicizing details they should otherwise conceal, or at least not flaunt. We should see millennials as "digital flâneurs," one social media critic argues, who share in order to catch the attention of their peers, which they long for ardently. ${ }^{36}$ And in doing so - paradoxically they betray concern for privacy. For, by issuing forth a mass of information, aren't they diverting our attention from other details, in the process? ${ }^{37}$ Aren't they hiding, in some fashion, behind the flood of data? This may be one way of achieving a degree of privacy in this data-ridden age. In all their sharing, millennials have simply figured out new ways to control the social situation, with the tools available to them.

While these are all compelling accounts behind digital sharing, I am generally dubious that it is so strategic and premeditated as some think, or contend. So much of it seems perfunctory and routine, and the revealed information so mundane and insignificant. Alternately, and as mentioned, people are so often prone to leaving posts that are unintentionally rude,

34 Krista Burton, "Are you really in love if it's not on Instagram?" New York Times, March 24, 2018: www.nytimes.com/2018/03/24/opinion/sunday/relationships-love-instagram.html.

35 Burton, "Are you really in love?"

$3^{6}$ danah boyd, It's Complicated: The Social Lives of Networked Teens (New Haven, CT: Yale University Press, 2014), 203.

37 See boyd, 75 . 
unthinkingly offensive - directed at wide audiences, to which they have put little apparent consideration. It's hard to see it as being much more than instinctual and reflexive, at this point.

Perhaps there is a simpler explanation to the phenomenon of online shamelessness that defies predictions for surveillance: people forget or ignore that they are watched. Thanks to the digital medium, which can be accessed and employed alone in one's room, behind four walls, it sustains the semblance of privacy. When I share online, I certainly seem to do so privately, or behind the protective layer of this medium. Or perhaps I may share anonymously, which means my identity seems even more secure. Digital communication is mediated communication, after all, where the mediation figures prominently - it is the computer or smartphone screen before me. This serves to remove me somehow from the target(s) of my emissions, and my audience. As a result, I feel I am at a remove when I divulge, or surveil others in turn. I might put it otherwise: there is a kind of epistemological disconnect at work here. To people who behave shamelessly online, they will affirm that they know someone is watching them - they will affirm that their actions are not concealed, but public in some fashion. Indeed, their emissions reach a broader population than if they had been shouted aloud in a public square. But it doesn't feel like this. It feels like their emissions are controlled, curated, and their author at safe remove from people he might hurt or offend or embarrass. Or as we see in the phenomenon of online trolling, people are emboldened by the perceived anonymity to wage destruction.

Technology writer Christine Rosen relays a story that illustrates the epistemological disconnect I have in mind. A college student reported to her a surprising encounter with a Facebook acquaintance: the acquaintance in question was of the opposite sex, and the student hardly knew her at all; she was one of countless friends party to his social media feed, and he had never spoken to her in person. But one day on campus, he bumped into her, and they struck up a conversation. He was shocked to find that he was sweating profusely, though it was not a hot day. "It wasn't until much later that I realized maybe I was sweating because I kind of liked her," he told Rosen, "and was off my game because she was right in front of me." ${ }^{8}$ Rosen goes on to argue that digital communication allows us to forget the kind of emotional signals - both those from our own bodies, and from others that typically punctuate and guide everyday public conversation. ${ }^{39}$ This example also points out how differently we view the digital medium, which causes us to

$3^{8}$ Christine Rosen, "Expose Thyself! On the Digitally Revealed Life," Hedgehog Review, 2o/1 (2016), https://iasc-culture.org/THR/THR_article_2018_Spring_Rosen.php.

39 Rosen, "Expose Thyself!" 
behave differently than when we are out in public - because digital communications seem private or safe - or safer. It is easy for me to feel "on my game," as the student puts it, when I am alone in my room composing clever comments online, behind the veil of a constructed personality perhaps, and feel little pressure to respond to anyone in front of me, in the moment. What's more, I may discover likeminded or sympathetic audiences online, and speak only to them - people for whom it's always easy to be "on my game."

In any case, the phenomenon of online sharing and shamelessness, our newfound culture of exposition, is a testament to how little we are concerned for privacy. Evidence of surveillance abounds; its presence is not hard to detect or infer in our daily lives. But it hardly deters anyone from divulging private details - habitually. To the contrary, this phenomenon suggests we may be immune to surveillance. Which is a fascinating prospect in itself. What would that mean for governments who harbor vast plans to spy on their people - as in China, which I will take up shortly? Why aim to monitor people if coercion is not the goal or anticipated result? Perhaps governments are happy to let us share and expose ourselves, and they will sit and watch and take it all in. Perhaps they don't want us to hide our true feelings and eccentricities at all, but live freely and openly, for all to see.

Despite this confessional culture, and the epistemological disconnect of digital communications, some of us do feel compelled to object when emissions are monitored, and private information collected and analyzed. The problem is, this compulsion is largely visceral. We may know when to object, but increasingly, we don't know how - we don't know what to say, how to articulate or express the harm that is inflicted by widespread government and commercial surveillance. And this is strange of course, because, again, we are steeped in a culture and tradition that supposedly prizes privacy - which is founded on it, we are told. Our difficulty in expressing the problem is evident in, among other things, a word that recurs in protests against surveillance schemes, which are dubbed "creepy."

The data broker Axciom engineered an extensive program to collect information on individuals, which it then sells to retailers who wish to know more about customers, actual and prospective. The program gathers information "continuously on approximately seven hundred million identifiable individuals," drawn from a few sources, including "Fortune 100 companies' records of people who "purchased something or signed up for a mailing list or some kind of offer," and "every data attribute you could gather publicly about consumers from public records." ${ }^{\circ}$ The breadth of this program spooked

40 Turow, 156. 
even a leading publication from the data brokerage industry itself, which fretted over the company's "aggressive quantification of individuals" that it deemed "creepy." 41

Retailers are increasingly interested in knowing where you are at any given moment. Thanks to beacon technology, they can outfit aisles with digital devices that communicate with your mobile phone, alerting where you are in the store, before which product, and then merchants can barrage you with pertinent and alluring promotions and discounts. ${ }^{42}$ Retailers will soon communicate with you in similar fashion whether you are in the parking lot about to enter the store, or simply driving by. ${ }^{43}$ They aim to deliver personalized messaging and marketing drawn from our detailed purchase history, or other available personal information amassed by data brokers and catalogued by retailers. The corporate entities engaged in this massive data collection recognize a "creepy factor" in what they do, but are ultimately confident that we can grow accustomed to it all, and be placated by the benefits we receive in turn. ${ }^{44}$

A privacy scholar ascribes a similar "creepiness factor" to the imminent networking of major devices and appliances in our homes, such as when "your heater or clothes dryer monitor how much power you're using, or ... your fridge [alerts] you that you're low on milk." 45 And the journalist covering a new startup deems it "creepy" for helping "landlords, employers and online dates strip-mine intimate data from your Facebook page." ${ }^{6}$ The company in question produces tenant reports for landlords, culled from social media sites of prospective tenants. The journalist composed her own tenant report, and was dismayed to find that it included a "list of my closest friends and interests, a percentage breakdown of my personality traits, a list of every time I've tweeted the words 'loan' and 'pregnant,' and the algorithm's confidence that I'll pay rent consistently." 47

Why is this kind of deep spying considered "creepy"? It suggests we are uncomfortable with it, of course, but to call it creepy is not to say it is wrong

41 Turow, 157.

42 Turow, 1.

43 Turow, 213.

44 Turow, 217.

45 David Lazarus, "Our privacy is losing out to Internet-connected household devices," LA Times, January 15, 2016, www.latimes.com/business/la-fi-lazarus-20160115-column.html.

$4^{6}$ Caitlin Dewey, "Creepy startup will help landlords, employers and online dates strip-mine intimate data from your Facebook page,” Washington Post, June 9, 2016, www.washingtonpost .com/news/the-intersect/wp/2016/o6/og/creepy-startup-will-help-landlords-employers-and-onlin e-dates-strip-mine-intimate-data-from-your-facebook-page/?utm_term=.8eodg7e8fadc.

47 Dewey, "Creepy startup." 
per se; it is to register worry, concern, doubt. When we say something is creepy, we mean to say we suspect it is wrong, or there is something potentially damaging or dangerous about it, but we are unsure what it is, and certainly cannot specify it. It is a feeling - a sense of being ill at ease.

We are uncomfortable - or at least, some of us are - with the prospect of constant and pervasive monitoring, of the most intimate and seemingly random details of our lives. But we do not know how to object any longer. Increasingly, many do not feel the need or urge to object at all. As I will soon show, objecting, or taking a harder stand on surveillance seems unlikely, and perhaps impossible given our dependence on digital technology - which will only grow. Facing this immense expansion of digital technology, which threatens our privacy at every turn, surveillance seems normal. If or when people do manage to object, they may do so out of a sense of obligation, a sense that this is what we as Americans are supposed to do. But in truth, the value of privacy seems lost on us.

This must be fixed if we would muster a defense of privacy. Attempts to impose regulations that give individuals more power over whether they can share private information are intolerably tenuous and, I fear, ultimately doomed so long as the majority no longer understands and appreciates privacy - clearly, convincingly, and self-consciously. 